7 - ORIGINAL ARTICLE

ISCHEMIA-REPERFUSION

\title{
Pentoxifylline associated to hypertonic saline solution attenuates inflammatory process and apoptosis after intestinal ischemia/reperfusion in rats ${ }^{1}$
}

\author{
Geraldo Magela Nogueira Marques ${ }^{\mathrm{I}}$, Roberto Rasslan ${ }^{\mathrm{II}}$, Alessandro Rodrigo Belon ${ }^{\mathrm{III}}$, Juliana Gonçalves Carvalho ${ }^{\mathrm{IV}}$, Raphael \\ Felice Netov $^{\text {, Samir Rasslan }}{ }^{\text {VI }}$, Edivaldo Massazo Utiyama ${ }^{\text {VII }}$, Edna Frasson de Souza Montero ${ }^{\text {VIII }}$
}

\author{
DOI: http://dx.doi.org/10.1590/S0102-86502014001800007
}

IFellow PhD degree, Postgraduate Program in Surgical Clinics, Laboratory of Surgical Physiopathology (LIM-62), Medical School, Sao Paulo University (USP), Brazil. Conception and design of the study, technical procedures, acquisition and interpretation of data, manuscript writing.

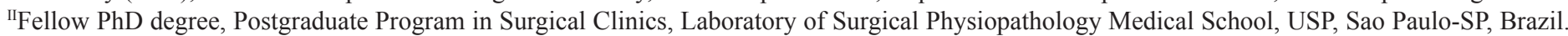
Technical procedures, interpretation of data.

IIIPhD, Researcher at Laboratory of Experimental Surgery (LIM-26), Medical School, USP, Sao Paulo-SP, Brazil. Technical procedures, interpretation of data.

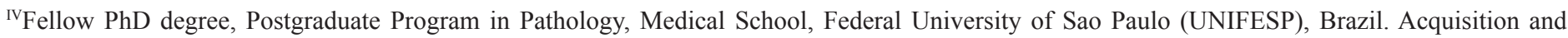
interpretation of data.

${ }^{v}$ Graduate student, School of Medicine, USP, Brazil. Grant from Institutional Program for Scientific Initiation (PIBIC) of the National Council of Technological and Scientific Development (CNPq), Ministry of Science, Technology and Inovation, Brazil. Technical procedures, acquisition of data. ${ }^{\mathrm{VI}}$ Full Professor, Department of Surgery, Medical School, USP, Sao Paulo-SP, Brazil. Interpretation of data, critical revision.

${ }^{\mathrm{VII}}$ Associate Professor, Department of Surgery, Medical School, USP, Sao Paulo-SP, Brazil. Interpretation of data, critical revision.

VIIIAssociate Professor, Department of Surgery, Laboratory of Surgical Research (LIM-62), Medical School, USP, and UNIFESP, Sao Paulo-SP, Brazil. Conception and design of the study, manuscript writing, critical revision.

\section{ABSTRACT}

PURPOSE: To evaluate intestinal inflammatory and apoptotic processes after intestinal ischemia/reperfusion injury, modulated by pentoxifylline and hypertonic saline.

METHODS: It was allocated into four groups ( $\mathrm{n}=6), 24$ male Wistar rats (200 to $250 \mathrm{~g}$ ) and submitted to intestinal ischemia for $40 \mathrm{~min}$ and reperfusion for $80 \mathrm{~min}$ : IR (did not receive any treatment); HS group (Hypertonic Saline, 4ml/kg-IV); PTX group (Pentoxifylline, 30mg/ kg-IV); HS+PTX group (Hypertonic Saline and Pentoxifylline). All animals were heparinized (100U/kg). At the end of reperfusion, ileal fragments were removed and stained on hematoxylin-eosin and histochemical studies for COX-2, Bcl-2 and cleaved caspase-3.

RESULTS: The values of $\mathrm{sO}_{2}$ were higher on treated groups at 40 minutes of reperfusion ( $\mathrm{p}=0.0081$ ) and 80 minutes of reperfusion $(\mathrm{p}=0.0072)$. Serum lactate values were lower on treated groups after 40 minutes of reperfusion $(\mathrm{p}=0.0003)$ and 80 minutes of reperfusion $(\mathrm{p}=0.0098)$. Morphologic tissue injuries showed higher grades on IR group versus other groups: HS ( $\mathrm{p}=0.0006), \mathrm{PTX}(\mathrm{p}=0.0433)$ and HS + PTX $(p=0.0040)$. The histochemical study showed lesser expression of COX-2 $(p=0.0015)$ and $\mathrm{Bcl}-2(\mathrm{p}=0.0012)$ on HS $+\mathrm{PTX}$ group. A lower expression of cleaved caspase-3 was demonstrated in PTX ( $\mathrm{p}=0.0090$; PTXvsIR).

CONCLUSION: The combined use of pentoxifylline and hypertonic saline offers best results on inflammatory and apoptotic inhibitory aspects after intestinal ischemia/reperfusion.

Key words: Reperfusion. Ischemia. Saline Solution, Hypertonic. Pentoxifylline. Apoptosis. Inflammation. Rats. 


\section{Introduction}

There is recent evidence suggesting that the choice of resuscitation strategy can also modulate the inflammatory response. Therefore, in terms of the inflammation, the type of fluid used to restore perfusion may be just as important as restoring perfusion itself. The protection of tissues subjected to I/R, as well as those who suffer the remote consequences, has been widely investigated. Some experimental protocols have shown benefits in using hypertonic saline (HS) associated to the anti-inflammatory properties of the nonspecific phosphodiesterase inhibitor pentoxifylline (PTX) on animals subjected to shock ${ }^{1,2}$.

Both substances, HS and PTX, present the property to decrease the TNF- $\alpha$ production and thereby inhibit the inflammatory cascade and COX-2 synthesis from arachidonic acid, softening the systemic inflammatory response that leads to multiple organ failure ${ }^{3,4}$. The expression of cleaved caspase- 3 and Bcl-2 are dynamically related to the phenomenon of apoptosis ${ }^{5}$. It has been demonstrated that the attenuation of TNF- $\alpha$ level induces higher expression of antiapoptotic protein $\mathrm{Bcl}-2$ and reduces the expression of cleaved caspase-3, a proapoptotic protein ${ }^{5,6}$.

Bearing in mind the results obtained by researchers in the association of HS and PTX in hemorhagic shock and sepsis, we hypothesized that HS and PTX association could protect intestine from mesenteric I/R by increasing antiapoptotic protein and reducing apoptosis deflagration and inflammatory process by reducing cytoplasmic expression of COX-2.

\section{Methods}

The research project was approved by the local Ethics Committee of the University of Sao Paulo Medical School (Process number: 120/2010). It was used 24 Wistar rats (Rattus norvegicus) weighing between 200 and $250 \mathrm{~g}$. The anesthesia was induced with intraperitoneal injection of ketamine $(50 \mathrm{mg} / \mathrm{kg})$ associated to xylazine $(10 \mathrm{mg} / \mathrm{kg})$ in the same syringe.

A right crural incision was made to dissect the femoral vessels. The femoral vein was canulated with a heparinized catheter (percutaneous 24-gauge catheter) for blood sampling and solutions infusion. Through a median laparotomy, the anterior or cranial mesenteric vessels were dissected and isolated. By this time, the animals received an intravenous injection of heparin (100U/ $\mathrm{kg}$ ). Intestinal ischemia was achieved by clamping the mesenteric vessels for 40 minutes. The clamp was removed and the animals were kept under observation for 80-minutes reperfusion.

Animals from IR group received $4 \mathrm{ml} / \mathrm{kg}$ of $0.9 \% \mathrm{NaCl}$ solution at the end of ischemia, HS Group received $4 \mathrm{ml} / \mathrm{kg}$ of $7.5 \%$ $\mathrm{NaCl}$ solution. PTX group received $30 \mathrm{mg} / \mathrm{kg}$ of pentoxifylline diluted in $4 \mathrm{ml} / \mathrm{kg} 0.9 \% \mathrm{NaCl}$. HS+PTX group received $30 \mathrm{mg} / \mathrm{kg}$ pentoxifylline diluted in $4 \mathrm{ml} / \mathrm{kg}$ hypertonic saline.

Blood samples for gas analysis were collected at I40 (end of ischemic period), R40 (intermediate time of the reperfusion period) and R80 (the end of the reperfusion period). At the end of the experiment, the animals were euthanized by lethal injection of $19.1 \% \mathrm{KCl}$ and the tissue samples were collected from the ileum of all animals for histology and immunohistochemistry. Tissue samples were dehydrated, embedded in paraffin, and cut into a series of $4 \mu \mathrm{m}$-thick slices. They were submitted either to hematoxylin and eosin (HE) or to imunohistochemistry staining for COX-2 (Cox$2^{(\mathrm{m}-19)}$, sc-1747, Santa Cruz, G2205, Monoclonal goat), cleaved caspase-3 (AP-1027 Anti cleaved caspase 3 (Asp 175), Calbiochem, D29363, Rabbit pAb) or Bcl-2 (Bcl-2 (c-2), sc-7382, Santa Cruz, J0203, Monoclonal mouse). The scoring system to intestinal tissue damage followed Chiu's ${ }^{7}$ criteria for intestinal mucosal injury. A immunohistochemistry score system was applied by combining the estimated percentage of immunoreactive cells (semi quantitative) with an intensity of staining estimate (qualitative) ${ }^{8}$. The results were ranked in four positions for statistical analysis.

Laboratory data were assessed using ANOVA and the differences were established by Bonferroni's post hoc test. Comparisons of data on histological scores were performed using the nonparametric Kruskal-Wallis test, followed by StudentNewman-Keuls post hoc test. The significance level was set at $p \leq .05$. All data are presented as mean \pm SEM.

\section{Results}

The oxygen saturation in the blood sample at the end of intestinal ischemia was similar among the four groups. After 40 minutes of reperfusion, the amount of $\mathrm{sO}_{2}$ in the IR group was much lower than other groups but with a significant difference only with $\mathrm{HS}$ and HS+PTX groups. Higher levels of $\mathrm{sO}_{2}$ at $\mathrm{R} 40$ on $\mathrm{HS}$ and HS+PTX groups set statistically significant differences compared to IR. This same pattern of differences remained until R80.

The values of serum lactate were lower on treated groups. In the first 40 minutes of reperfusion, the values of serum lactate had similar behavior, with a slight increase compared to the initial value in the three treated groups, establishing significant difference compared to the IR group. At the end of the observation time, the PTX group differed from the other groups treated with elevation of serum lactate value, resembling the IR group and maintaining significant difference versus the HS and HS+PTX groups (Table 1). 
TABLE 1 - Values of serum Lactate $(\mathrm{mg} / \mathrm{dl})$ and arterial blood $\mathrm{sO}_{2}(\%)$, both expressed as median $\pm \mathrm{SE}$, at the different moments of the study in each group.

\begin{tabular}{lcccccc}
\hline Moment & Parameters & $\boldsymbol{I R}$ & $\boldsymbol{H S}$ & $\boldsymbol{P T X}$ & $\boldsymbol{H S}+\boldsymbol{P T X}$ & $\boldsymbol{P}$ value \\
\hline I40 & $\mathrm{sO}_{2}$ & $96.6 \pm 1.1$ & $97.4 \pm 1.2$ & $97.3 \pm 1.0$ & $97.4 \pm 0.3$ & 0.1887 \\
& Lactate & $6.8 \pm 2.1$ & $5.3 \pm 1.8$ & $4.3 \pm 1.0$ & $6.2 \pm 1.2$ & 0.1370 \\
\multirow{2}{*}{$\mathbf{R 4 0}$} & $\mathrm{SO}_{2}$ & $94.8 \pm 3.7$ & $98.7 \pm 1.0^{*}$ & $97.2 \pm 1.0^{*}$ & $98.9 \pm 1.3^{*}$ & $\mathbf{0 . 0 0 9 9}$ \\
& $\mathrm{Lactate}^{*}$ & $25.7 \pm 9.9$ & $7.3 \pm 2.4^{*}$ & $12.5 \pm 6.5^{*}$ & $9.8 \pm 3.7^{*}$ & $\mathbf{0 . 0 0 6 9}$ \\
$\mathbf{R} 80$ & $\mathrm{SO}_{2}$ & $95.8 \pm 2.1$ & $98.7 \pm 1.0^{*}$ & $96.7 \pm 0.6^{*}$ & $98.2 \pm 1.5^{*}$ & $\mathbf{0 . 0 0 7 4}$ \\
& Lactate & $34.3 \pm 18.8$ & $10.17 \pm 3.4^{*}$ & $29.8 \pm 19.3$ & $14.0 \pm 7.4^{*}$ & $\mathbf{0 . 0 0 9 8}$ \\
\hline
\end{tabular}

Analysis of variance (ANOVA) and Bonferroni's post hoc Test $\left({ }^{*}=\mathrm{p}<0.05 v s\right.$ IR)

The degree of tissue damage, according to Chiu's criteria, was lower in the intestinal tissue of treated animals. IR group, which presented the highest degree of tissue damage, set statistically significant differences versus HS ( $\mathrm{p}=0.0200)$, PTX $(p=0.0200)$ and HS+PTX $(p=0.0412)$ in intestinal tissue samples (Figure 1A, B and C).

The inflammatory process, studied through immunohistochemical COX-2 staining, resulted in similar cytoplasmic labeling for IR, HS and PTX groups. Only the HS + PTX group established statistically significance versus
IR, highlighting the decrease of inflammatory process with combination therapy ( $\mathrm{p}=0.0015)$ (Figure 2A, B and C).

For immunohistochemical study of apoptosis, Caspase-3 showed that HS group had the lowest cytoplasmic expression and it was the only one to establish a significant difference versus IR ( $\mathrm{p}=0.0145)$ (Figure $3 \mathrm{~A}, \mathrm{~B}$ and $\mathrm{C}$ ). In contrast, in the immunohistochemical staining for Bcl-2, although the groups HS and PTX present almost two fold cytoplasmic expression than IR group, only the HS+PTX group was able to establish a significant difference $(\mathrm{p}=0.0047)$ (Figure 4A, B and C).
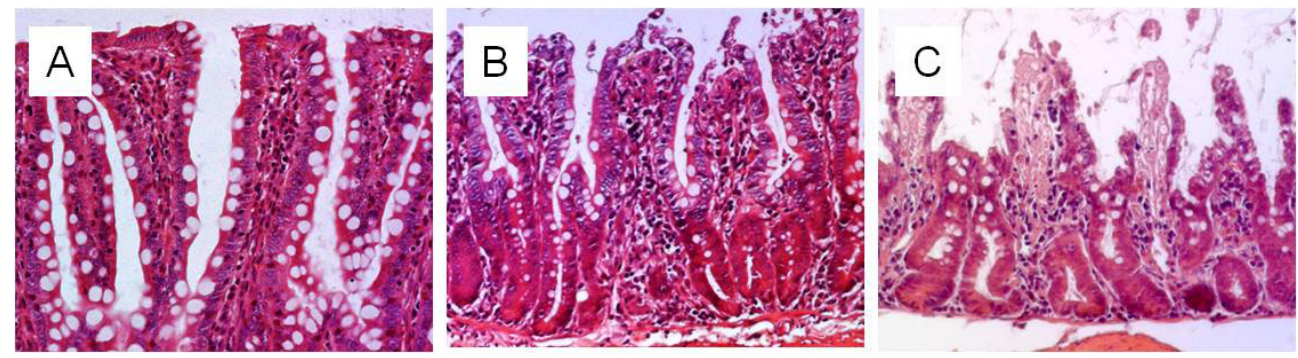

FIGURE 1 - Ileal photomicrographs, HE staining, x200. A. HS Group, normal architecture. B. HS+PTX Group, moderate mucosal injury. C. IR Group, Intense mucosal injury.
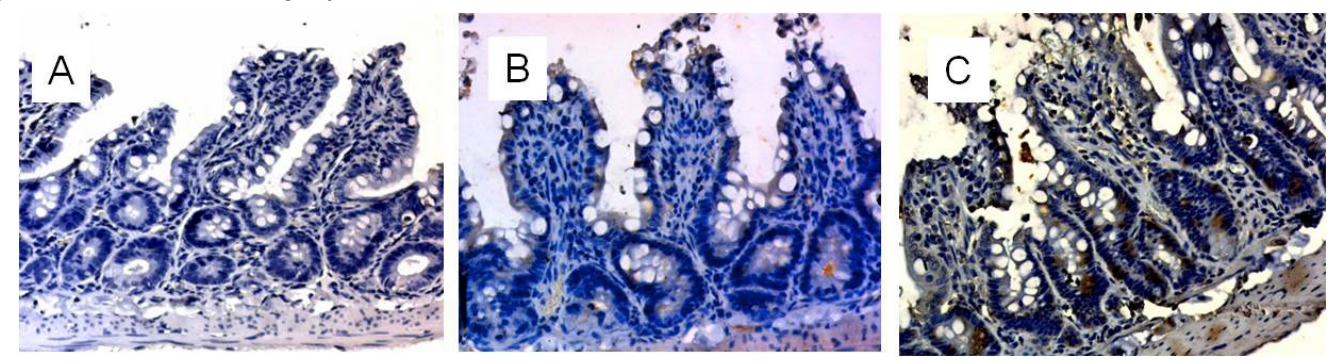

FIGURE 2 - COX-2 immunostaining, x200. A. HS+PTX Group, mild cytoplasmic staining. B. PTX Group, moderate cytoplasmic staining. C. IR Group, intense cytoplasmic staining.

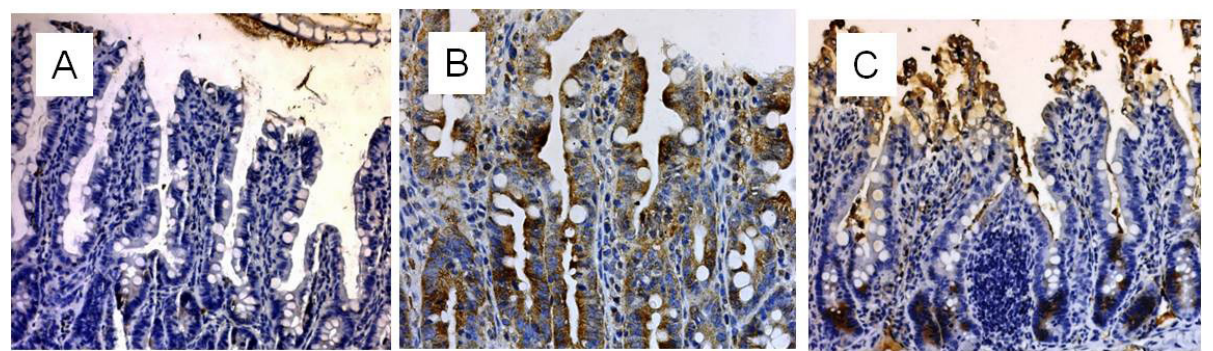

FIGURE 3 - Caspase-3 immunostaining, x200. A. HS Group, mild cytoplasmic staining. B. HS Group, moderate cytoplasmic staining. C. IR Group, Intense cytoplasmic staining. 


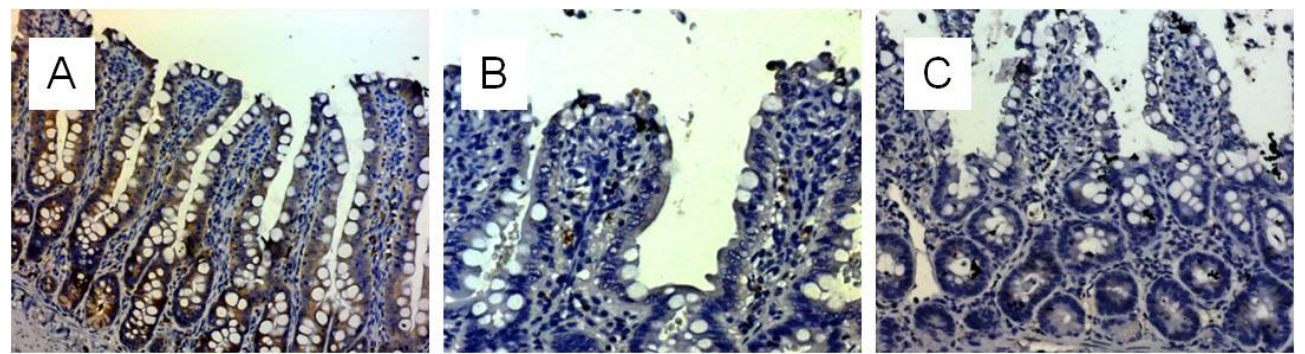

FIGURE 4 - Bcl-2 immunostaining, x200. A. HS+PTX Group, intense cytoplasmic staining. B. PTX Group, moderate cytoplasmic staining. C. IR Group, mild cytoplasmic staining.

\section{Discussion}

Several experimental models were described to study ischemia and reperfusion. Rats are the most commonly used experimental animal, since its splanchnic circulation has similarities to the human being's. Some extrapolation of information from one species to another may be considered ${ }^{10}$. While comparing the types of vascular occlusion, mesenteric artery, mesenteric vein and the occlusion of both mesenteric vessels, higher mortality of rats was reported on exclusively arterial occlusion. Moreover, greater degree of intestinal mucosa damage in isolated venous occlusion has been seen versus arterial occlusion. Similar insults, local or remote, result from the occlusion of both mesenteric vessels ${ }^{11,12}$. The occlusion of both mesenteric artery and vein can cause significant injury in the intestine and remote organs and may develop into multiple organ dysfunction syndrome (MODS) ${ }^{13}$.

Several substances have been used to try to reduce the degree of tissue damage caused by reperfusion. With different mechanisms of action, the aim is to eliminate or to reduce the production of ROS, interleukins, tumor necrosis factor alpha (TNF- $\alpha$ ), platelet activating factor and adhesion molecules ${ }^{14,15}$. HS applied to animals subjected to I/R by shock presented more advantages over normal saline ${ }^{16}$. The main sources of expansion of the plasma after HS infusion are the endothelial cells and erythrocytes that may lose approximately $8 \%$ of their volume into the intravascular compartment. This volume transition would result in important hemorheological effects for microcirculation since the reduction of both, red blood cells and endothelium swelling, decrease blood viscosity and microcirculation hydraulic resistance ${ }^{17}$. HS shows rheological effect by increasing the deformability of red blood cells and reducing blood shear force as a result of viscosity improvement ${ }^{18}$.

In mesenteric $\mathrm{I} / \mathrm{R}$, pentoxifylline induces reduction of malondialdehyde in tissue, the final product of lipid peroxidation, and overexpression of glutathione, an antioxidant agent ${ }^{14}$. It maintains endothelial cell function during sepsis and reduces plasma concentration of cytokines. Since the pentoxifylline is also capable of improving hemorheology by restoring red blood cells deformability, it has been used in clinical and experimental I/R studies and results on improvement of circulatory parameters and oxygen delivery to tissue ${ }^{19,20}$. The recovery of hemorheological properties (increased deformation capacity of red blood cells and decreased blood viscosity) restores blood flow more quickly and improves oxygen delivery to tissue. The amount of blood that contains a fraction of red blood cells with reduced flexibility comes from the arterioles with significantly less oxygen than blood with $100 \%$ normal red blood cells at the same hemoglobin concentration. This phenomenon suggests that hardened red cells get less oxygen on its passage through the lung characterizing that the diffusing capacity of oxygen is directly related to red blood cells deformability ${ }^{21,22}$.

Considering the hemorheological properties described above, pentoxifylline was not able to improve oxygen uptake in pulmonary arterioles by improving red blood cells deformability. However, when two hemorheological parameters were improved (deformability and viscosity), as previously described in the joint use of HS and PTX, red cells begun to acquire greater amount of oxygen in the pulmonary arterioles in accordance to the obtained results.

Serum lactate, compared to $\mathrm{BE}, \mathrm{BIC}$ and $\mathrm{pH}$, is more effective in the evaluation of metabolic acidosis. This could be attributed to the large amount of physiological compensatory mechanisms to maintain the values of $\mathrm{BE}, \mathrm{BIC}$ and $\mathrm{pH}$ within the normal range ${ }^{23}$. The lactate levels are directly and clearly related to the degree of splanchnic hypoperfusion ${ }^{24,25}$.

HS infusion can be considered as a resuscitation factor by promoting intravascular compartment expansion and consequent microcirculatory parameters improvement, as already stated before ${ }^{17}$. Tissues react with decreased lactate production and serum lactate levels are reduced as liver metabolism is restored ${ }^{24}$. In the PTX group the "resuscitation factors" cited above has not been implemented and it justifies increased serum lactate levels at the end of reperfusion period. Pentoxifylline property of inhibiting 
TNF- $\alpha$ has been demonstrated ${ }^{15}$. In experimental NEC model in rats, authors found that pentoxifylline was able to significantly attenuate the degree of injury to the intestinal mucosa. Chiu's criteria $^{9}$ for intestinal lesion caused by $\mathrm{I} / \mathrm{R}$ was used in this study and showed that the IR group developed a higher degree of intestinal mucosa damage, in accordance with existing literature.

The anti-inflammatory action of hypertonic saline has been demonstrated by its experimental use in some diseases and after mesenteric $\mathrm{I} / \mathrm{R}^{3}$. HS in experimental acute pancreatitis in rats decreases the expression of COX-2 and serum levels of TNF- $\alpha$ by sandwich ELISA from tissue homogenates in treated animals compared to untreated ones or the animals that received isotonic saline ${ }^{3}$. Both substances, HS and PTX, present the property to decrease TNF- $\alpha$ production and thereby inhibit the inflammatory cascade and COX-2 synthesis from arachidonic acid, softening the systemic inflammatory response that leads to multiple organ failure syndrome ${ }^{3,26}$. Blocking the production of TNF- $\alpha$ by pentoxifylline takes place by activation of adenyl cyclase and increased levels of intracellular c-AMP. This in turn decreases the amount of arachidonic acid that undergoes peroxidation. The overall effect is a decrease in systemic and local concentrations of inflammatory agents such as cyclooxygenase $\mathrm{e}^{4,27}$. The addition of anti-inflammatory effects of the solutions in the HS+PTX group was sufficient to reduce inflammation, and it did not occur in the groups in which solutions were used separately (HS and PTX).

As TNF- $\alpha$ is an inducer of the inflammatory cascade, it also acts as trigger to the extrinsic pathway of apoptosis ${ }^{28,29}$. On cell death after I/R injury, apoptosis and necrosis coexist. In necrosis, cell membrane loses its integrity and intracellular contents generally overflow, causing inflammation of the surrounding tissue. In apoptosis, the cell membrane remains intact and the cell is rapidly phagocytosed without leakage of its contents and without triggering an inflammatory reaction ${ }^{30}$. Inhibition of tissue damage and consequent cell death in ischemic bowel syndrome may not only reduce the amount of the intestine to be resected but also affect the severity of the inflammatory response $\mathrm{e}^{31}$.

The use of caspase inhibitors have little effect on cells damaged to necrosis. However, they can allow recovery of a cell population that were moderately damaged and that would undergo apoptosis. The rescue of damaged cells may have significance in terms of organ function and systemic effects of tissue injury ${ }^{31}$. Evaluation of cytoplasmic expression of cleaved caspase- 3 in intestinal tissue of animals subjected to $\mathrm{I} / \mathrm{R}$ revealed that there was less apoptotic deflagration in SH group. The expression of cleaved caspase- 3 is sometimes misinterpreted since the occurrence of severe tissue damage leads to cell death by necrosis and thus, apoptosis would be less pronounced ${ }^{32}$. Furthermore, apoptosis is a cell death mechanism that depends on ATP. Depletion of this energy source would lead pro apoptotic proteins underexpression. The recovery of energy supply can promote tissue recovery and thereby apoptosis, as a mechanism of regeneration, could be overestimated ${ }^{1}$.

The expression of cleaved caspase- 3 and Bcl-2 are dynamically related to the phenomenon of apoptosis ${ }^{5}$. Bcl-2 acts as anti-apoptotic regulator to prevent or delay the release of cytochrome c, perhaps by its ability to affect the establishment or maintenance of mitochondrial membrane channels function ${ }^{33}$. Interventions to elevate the levels of $\mathrm{Bcl}-2$ or to improve its function would be useful to reduce damage caused not only by $\mathrm{I} / \mathrm{R}$ but also for other apoptosis inducing factors such as $\gamma$ irradiation. In this study, the three treated groups showed higher expression of Bcl-2 in immunohistochemical analysis of intestinal tissue. Although the degree of expression in HS and PTX groups were about two fold higher than the IR group, only the HS+PTX group showed a statistically significant difference versus IR group.

The evaluation of the anti-apoptotic protein (Bcl-2) showed a protection that treatment could provide to tissues. It was observed a synergistic effect between HS and PTX, which probably resulted from the improvement in splanchnic circulation and restoration of intestinal microcirculation, with further reduction in erythrocytes and entotelial cells edema, increased mucosal oxygenation and reduced production of cytokines, particularly TNF- $\alpha$, and ROS. Hemorrheological factors could be involved in the preservation of the intestinal wall, increasing expression of Bcl-2 by determining the blockade on the the outbreak of apoptosis as a mecanism of more intense aggression by the mesenteric I/R, such as, restored erythrocytes deformation capacity, reduction on blood viscosity and thus blood shear force ${ }^{15,18,34}$.

Despite recent clinical and laboratory studies on intestinal $\mathrm{I} / \mathrm{R}$ with pentoxifylline and hypertonic saline, and the regular use of these substances in hospitals, mechanisms of action and association with drugs and procedures must be studied carefully to better understand the consequences of interventions in ischemia and reperfusion in mesenteric territory. The prevention of remote organ damage remains a challenge to be overcome.

\section{Conclusion}

The use of pentoxifylline associated to hypertonic saline $(7.5 \%)$ on intestinal ischemia/reperfusion offered the best protection to tissues in intestinal tissue by attenuating metabolic aspects, diminishing tissue injury scores, decreasing inflammatory response and apoptosis. 


\section{References}

1. Gonzalez EA, Kozar RA, Suliburk JW, Weisbrodt NW, Mercer DW, Moore FA. Conventional dose hypertonic saline provides optimal gut protection and limits remote organ injury after gut ischemia reperfusion. J Trauma. 2006 Jul;61(1):66-73. doi: 10.1097/01.ta. 0000224190.65542.e2.

2. Jonas J, Heimann A, Strecker U, Kempski O. Hypertonic/hyperoncotic resuscitation after intestinal superior mesenteric artery occlusion: early effects on circulation and intestinal reperfusion. Shock. 2000 Jul;14(1):24-9. PMID: 10909889.

3. Coelho AM, Jukemura J, Sampietre SN, Martins JO, Molan NA, Patzina RA, Lindkvist B, Jancar S, Cunha JE, D'Albuquerque LA, Machado MC. . Mechanisms of the beneficial effect of hypertonic saline solution in acute pancreatitis. Shock. 2010 Nov;34(5):502-7. doi: 0.1097/ SHK.0b013e3181defaa1.

4. Abdel-Salam OM, Baiuomy AR, El-Shenawy SM, Arbid MS. The anti-inflammatory effects of the phosphodiesterase inhibitor pentoxifylline in the rat. Pharmacol Res. 2003 Apr;47(4):331-40. doi: 10.1016/S1043-6618(03)00002-1.

5. Aban N, Cinel L, Tamer L, Aktas A, Aban M. Ischemic preconditioning reduces caspase-related intestinal apoptosis. Surg Today. 2005;35(3):228-34. doi: 10.1007/s00595-004-2918-y.

6. Mondello S, Galuppo M, Mazzon E, Domenico I, Mondello P, Carmela A, Cuzzocrea S. Glutamine treatment attenuates the development of ischaemia/reperfusion injury of the gut. Eur J Pharmacol. 2010 Sep 25;643(2-3):304-15. doi: 10.1016/j. ejphar.2010.06.044.

7. Chiu CJ, Scott HJ, Gurd FN. Circulatory collapse following the restoration of blood flow to the occluded superior mesenteric artery. Surg Forum. 1970;21:47-9. PMID: 5514918.

8. Perrone G, Santini D, Zagami M, Vincenzi B, Verzi A, Morini S, Borzomati D, Coppola R, Antinori A, Magistrelli P, Tonini G, Rabitti C. COX-2 expression of ampullary carcinoma: correlation with different histotypes and clinicopathological parameters. Virchows Arch. 2006 Sep;449(3):334-40. doi: 10.1007/s00428-006-0255-9.

9. Chiu CJ, McArdle AH, Brown R, Scott HJ, Gurd FN. Intestinal mucosal lesion in low-flow states. I. A morphological, hemodynamic, and metabolic reappraisal. Arch Surg. 1970 Oct; 101(4):478-83. doi: 10.1001/archsurg.1970.01340280030009.

10. Cerqueira NF, Hussni CA, Yoshida WB, Padovani CR. Systemic evaluation on ischemia and reperfusion injury of splanchnic organs in rats. Acta Cir Bras. 2009 Jul-Aug;24(4):290-5. doi: $10.1590 /$ S0102-86502009000400008.

11. Guzman-de la Garza FJ, Camara-Lemarroy CR, Alarcon-Galvan G, Cordero-Perez P, Munoz- Espinosa LE, Fernandez-Garza NE. Different patterns of intestinal response to injury after arterial, venous or arteriovenous occlusion in rats. World J Gastroenterol 2009 Aug 21;15(31):3901-7. doi: 10.3748/wjg.15.3901.

12. Vincenti M, Behrends M, Dang K, Park YH, Hirose R, BlasiIbanez A, Liu T, Serkova NJ, Niemann CU. Induction of intestinal ischemia reperfusion injury by portal vein outflow occlusion in rats. J Gastroenterol. 2010 Nov;45(11):1103-10. doi: 10.1007/s00535010-0262-0.

13. Higa OH, Parra ER, Ab'Saber AM, Farhat C, Higa R, Capelozzi VL. Protective effects of ascorbic acid pretreatment in a rat model of intestinal ischemia-reperfusion injury: a histomorphometric study. Clinics (Sao Paulo). 2007 Jun;62(3):315-20. doi: 10.1590/S180759322007000300017

14. Sener G, Akgun U, Satiroglu H, Topaloglu U, Keyer-Uysal M. The effect of pentoxifylline on intestinal ischemia/reperfusion injury. Fundam Clin Pharmacol. 2001 Feb;15(1):19-22. doi: 10.1046/j.1472-8206.2001.00007.x.
15. Travadi J, Patole S, Charles A, Dvorak B, Doherty D, Simmer K. Pentoxifylline reduces the incidence and severity of necrotizing enterocolitis in a neonatal rat model. Pediatr Res. 2006 Aug;60(2):185-9. doi: 10.1203/01.pdr.0000228325.24945.ac.

16. Velasco IT, Pontieri V, Rocha e Silva M, Jr., Lopes OU. Hyperosmotic $\mathrm{NaCl}$ and severe hemorrhagic shock. Am J Physiol. 1980 Nov;239(5):H664-73. PMID: 6776826.

17. Rocha-e-Silva M, Poli de Figueiredo LF. Small volume hypertonic resuscitation of circulatory shock. Clinics (Sao Paulo). 2005 Apr;60(2):159-72. doi: 10.1590/S1807-59322005000200013.

18. Zhao L, Wang B, You G, Wang Z, Zhou H. Effects of different resuscitation fluids on the rheologic behavior of red blood cells, blood viscosity and plasma viscosity in experimental hemorrhagic shock. Resuscitation. 2009 Feb;80(2):253-8. doi: 10.1016/j. resuscitation. 2008.10.014

19. Horvath B, Vekasi J, Kesmarky G, Toth K. In vitro antioxidant properties of pentoxifylline and vinpocetine in a rheological model. Clin Hemorheol Microcirc. 2008;40(2):165-6. doi: 10.3233/CH2008-1123.

20. Muravyov AV, Yakusevich VV, Chuchkanov FA, Maimistova AA, Bulaeva SV, Zaitsev LG. Hemorheological efficiency of drugs, targeting on intracellular phosphodiesterase activity: in vitro study. Clin Hemorheol Microcirc. 2007;36(4):327-34. PMID: 17502703.

21. Cabrales P. Effects of erythrocyte flexibility on microvascular perfusion and oxygenation during acute anemia. Am J Physiol Heart Circ Physiol. 2007 Aug;293(2):H1206-15. doi: 10.1152/ ajpheart.00109.2007.

22. Betticher DC, Reinhart WH, Geiser J. Effect of RBC shape and deformability on pulmonary $\mathrm{O} 2$ diffusing capacity and resistance to flow in rabbit lungs. J Appl Physiol. 1995 Mar;78(3):778-83. PMID: 7775318

23. Englehart MS, Schreiber MA. Measurement of acid-base resuscitation endpoints: lactate, base deficit, bicarbonate or what? Curr Opin Crit Care. 2006 Dec;12(6):569-74. doi: 10.1097/ MCC.0b013e328010ba4f.

24. Kadam P, Patil N, Bhate J, Pantvaidya S, Jagtap SM. The serial estimation of serum lactate, pyruvate, and base deficit in trauma patients with adequate resuscitation and management. Indian J Anesth. 2004 Apr;48(2):138-41. http://medind.nic.in/iad/t04/i2/ iadt04i2p138.pdf

25. Marqui CE, Silva HC, Ferez D, Cavassani SS, Moraes JB, Silva DA, Simoes RS, Lopes CA, Taha MO, Oliveira-Junior IS. Pretreatment with pentoxifylline attenuates lung injury induced by intestinal ischemia/reperfusion in rats. Acta Cir Bras. 2011 Dec;26(6):438-44. doi: 10.1590/S0102-86502011000600006.

26. Vincenzi R, Cepeda LA, Pirani WM, Sannomyia P, Rocha ESM, Cruz RJ, Jr. Small volume resuscitation with 3\% hypertonic saline solution decrease inflammatory response and attenuates end organ damage after controlled hemorrhagic shock. Am J Surg. 2009 Sep;198(3):407-14. doi: 10.1016/j.amjsurg.2009.01.017.

27. Modzelewski B, Janiak A. Pentoxyphilline as a cyclooxygenase (cox-2) inhibitor in experimental sepsis. Med Sci Monit. 2004 Jul;10(7):BR233-7. PMID: 15232498.

28. An S, Hishikawa Y, Liu J, Koji T. Lung injury after ischemiareperfusion of small intestine in rats involves apoptosis of type II alveolar epithelial cells mediated by TNF-alpha and activation of Bid pathway. Apoptosis. 2007 Nov;12(11):1989-2001. doi: 10.1007/ s10495-007-0125-1.

29. Fulda S, Debatin KM. Extrinsic versus intrinsic apoptosis pathways in anticancer chemotherapy. Oncogene. 2006 Aug 7;25(34):4798811. doi: 10.1038/sj.onc. 1209608 .

30. Zhou Y, Wang Q, Evers BM, Chung DH. Signal transduction pathways involved in oxidative stress-induced intestinal epithelial 
cell apoptosis. Pediatr Res. 2005 Dec;58(6):1192-7. doi: 10.1038/ sj.onc. 1209608 .

31. Farber A, Connors JP, Friedlander RM, Wagner RJ, Powell RJ, Cronenwett JL. A specific inhibitor of apoptosis decreases tissue injury after intestinal ischemia-reperfusion in mice. J Vasc Surg. 1999 Oct;30(4):752-60. PMID: 10514215.

32. Jilling T, Lu J, Jackson M, Caplan MS. Intestinal epithelial apoptosis initiates gross bowel necrosis in an experimental rat model of neonatal necrotizing enterocolitis. Pediatr Res. 2004 Apr;55(4):622-9. doi: 10.1203/01.PDR.0000113463.70435.74.

33. Coopersmith CM, O'Donnell D, Gordon JI. Bcl-2 inhibits ischemiareperfusion-induced apoptosis in the intestinal epithelium of transgenic mice. Am J Physiol. 1999 Mar;276 (3):677-86. PMID: 10070044.

34. Ernst E. Haemorheological treatment of ischaemia--facts or fancy? J R Soc Med. 1991 Nov; 84(11):639-40. PMID: 1744864.

\section{Acknowledgement}

To Celina Tizuko Fujiyama Oshima, PhD, Researcher responsible for the laboratory of Molecular Pathology, UNIFESP, for her support and generosity in performing the immunohistochemistry slides.

\section{Correspondence:}

Edna Frasson de Souza Montero

Alameda Espada, Residência Onze

06540-395 Santana do Parnaíba - SP Brasil

Tel.: (55 11)3061-7216

edna.montero@gmail.com

Received: June 10, 2014

Review: Aug 12, 2014

Accepted: Sep 11, 2014

Conflict of interest: none

Financial source: none

'Research performed at Laboratory of Medical Investigation \#62 and \#26, Sao Paulo University (USP), Brazil. Part of PhD degree thesis, Postgraduate Program in Surgical Clinics, USP. Tutor: Edna Frasson de Souza Montero. 